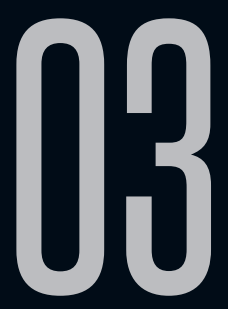

\title{
HISTORIA DE LO FANTÁSTICO EN LA CULTURA ESPAÑOLA CONTEMPORÁNEA (1900-2015). DAVID ROAS (ORG.) 2017
}

Maira Angélica Pandolfi

Recebido em 05 fev 2018. Maira Angélica Pandolfi é licenciada em Letras, Aprovado em 18 mai 2018. Português/Espanhol (1997), Mestre (2000) com a Dissertação sobre "A Recepção Crítica de Manuel Antônio Álvares de Azevedo (1852-1999)", apoiada pela FAPESP, e Doutora (2006) com a tese "Leituras e Releituras Românticas: José de Espronceda e Álvares de Azevedo" pela UNESP-Campus de Assis, onde também é docente, atuando na Graduação e na Pós-Graduação. É Professora Assistente Doutora no Departamento de Letras Modernas desde 2010, na área de Língua e Literaturas de Língua Espanhola; foi Vice-Coordenadora do Programa de Pós-Graduação em Letras da Unesp-Assis (2013 a 2016). Realizou Estágio de Pesquisa na Universidad de Salamanca/ Espanha (2013). É membro da Associação Brasileira de Hispanistas (ABH); do Grupo de Estudos Linguísticos (GEL), do GT ANPOLL Vertentes do Insólito Ficcional e do Grupo Vertentes do Fantástico na Literatura. É líder do Grupo de Pesquisa Narrativas Estrangeiras Modernas, cadastrado no CNPq e Vice-Líder do Grupo de Estudos Bakhtinianos, cadastrado no CNPq. Atualmente leciona apenas Literaturas de Língua Espanhola e suas pesquisas estão voltadas para essa área de estudos e para a literatura comparada, com ênfase em produções contemporâneas onde figuram 
o insólito e o fantástico. Têm vários estudos sobre Mitos Literários Espanhóis, adaptações e recriações desses mitos em literaturas de língua espanhola e também na literatura brasileira. 
Historia de lo fantástico en la cultura española contemporánea (1900-2015) é uma obra organizada por David Roas, dividida em 14 capítulos escritos por autores diversos, alguns deles com a participação de Roas. No primeiro capítulo, intitulado "El cuento modernista", Ana Casas tece uma ampla teia de conexões que relacionam as diversificadas formas de manifestação do fantástico na virada

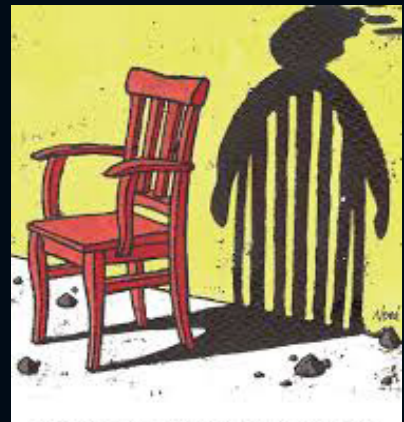
Historia de lo fantástico en ia cuturs espanola conkemporsmea (1900-2015) Dwo fores (Dea.) do século XIX ao XX, apontando a influência da psiquiatria, de Poe, de Hoffmann, do cientificismo positivista, da ascensão do espiritismo e do esoterismo. A virada do século também fomentou contos de base folclórica e lendária, como os de Valle Inclán e Pío Baroja, que questionam traços de perversidade sexual no âmbito familiar, a necrofilia, o satanismo, o erotismo religioso, dentre outros. Uma marca característica desses relatos é a ambiguidade, sobre a qual Ana Casas apresenta algumas reflexões conclusivas que aportam luz ao fenômeno, ou seja, que propõem uma discussão dialética entre a fé e o ceticismo, já que as narrativas desse período aludem a uma insatisfação com o realismo e com o positivismo vigentes na segunda metade do XIX, pois ao mesmo tempo em que não negam os princípios científicos também questionam os limites dessa ciência como instrumento único para captar a realidade. Tomando como referência os estudos de Rosalba Campra, detalha aspectos peculiares à retórica do fantástico modernista, que apresenta adjetivação fortemente conotada, presença de metáforas que refletem a alma atormentada dos protagonistas e 
a reunião de diversas vozes que acrescentam distintos pontos de vista ao acontecimento sobrenatural. Também merece destaque, segundo Casas, a maneira com que os relatos da virada do século representam a realidade, por meio de um tratamento superficial do aspecto psicológico dos protagonistas, a fim de aludir a uma realidade tão misteriosa quanto o ser que a habita e irrompendo, assim, os símbolos e as imagens de ressonância sobrenatural. Para a autora, as sobreposições de campos semânticos distintos e até mesmo incompatíveis para a descrição de uma dada realidade ou objeto torna o fantástico moderno bastante insólito.

No segundo capítulo, Alfons Gregori comenta as produções narrativas de 1930 a 1950. Nesse percurso, o autor destaca a importância das vanguardas em uma literatura tradicionalmente considerada avessa às formas não miméticas. Fundamentando-se em Martín Rodrígues, o autor desse capítulo refere-se a quatro correntes narrativas do período selecionado que se afastam da literatura espanhola realista: o romance lírico de Azorín ou Gabriel Miró; o romance desumanizado e vanguardista de Ortega y Gasset; o romance humorístico e as ficções intelectuais de Pérez de Ayala ou Benjamin Jarnés. Fato curioso é que a narrativa fantástica não aparece entre essas quatro correntes por não ser considerada de caráter culto ou elitista, posto que o gênero fantástico identificava-se com uma literatura de massa ou de mercado, destinada a um grande público e editada em revistas populares como Novela de Hoy. Também cresce a literatura de ficção científica. É preciso ressaltar, segundo Gregori, que a perpetuação e vigor do gênero fantástico nesse contexto tiveram como grande propulsor as traduções e reedições de romances 
curtos e coleções de relatos populares não miméticos. São coleções que reúnem grandes nomes da literatura fantástica como Poe, Hoffmann, Gautier, Washington Irving, Bram Stoker. Algumas coleções que tinham como título La novela fantástica eram, na verdade, romances de aventura, de ficção científica e recriações míticas. Sobre as criações fantásticas da década de 30 em língua castelhana, Gregori menciona duas maneiras distintas de fazer despontar o sobrenatural, ora por meio de personagens clássicas como o diabo, ora pelas histórias de fantasmas. Diversos elementos da matéria artúrica também são reaproveitados pelo renomado escritor Álvaro Cunqueiro, na modalidade narrativa do maravilhoso. Nas narrativas de caráter humorístico, percebese uma estreita ligação com as vertentes vanguardistas. Nesse contexto, destaca-se um grupo de artistas reconhecidos como "A outra geração de 27", cuja liderança é atribuída a Ramón Gómez de la Serna. São requintadas estratégias que vão salpicando o fantástico moderno de recursos habituais nas literaturas de vanguarda, tais como a metáfora literal, a conjunção sinestésica, a objetivação de elementos abstratos e a personificação de objetos, a reescritura paródica de velhos mitos e/ou a paródia do maravilhoso cristão. São tratados aqui os autores e obras de maior destaque durante as décadas de 30, 40 e 50. Muito significativa, ainda, é a sugestão investigativa deixada por Gregori ao aludir à existência de um fantástico subterrâneo, cultivado nesses anos de fascismo ultra-católico e tradicionalista. Por essas razões políticas e pelo difícil acesso a esses textos, eles foram pouco divulgados e ainda se encontram no limbo, constituindo uma lacuna a ser preenchida pela crítica literária do fantástico. 
O terceiro capítulo, que desenha o panorama da narrativa fantástica espanhola nas décadas de 1950 e 1960, fica a cargo dos três estudiosos que redigiram, separadamente, os capítulos anteriores: David Roas, Ana Casas e Alfons Gregori. Todos ressaltam a sobrevivência e a constância da vertente não mimética da literatura espanhola, apesar do inegável predomínio da estética realista na segunda metade século $X X$. Dentre as produções não miméticas continuam gozando de grande interesse, nas décadas em questão, as formas do maravilhoso e do absurdo, levadas adiante pelo já mencionado Álvaro Cunqueiro e também por Joan Perucho, José Maria Gironella, Camilo José Cela e Vicente Risco. Já na órbita do absurdo se encontram autores como Carlos Edmundo de Ory, José Luis Sampedro, Francisco Fernández-Santos, Ventura Doreste, Miguel Buñuel e Gonzalo Fortea. Segundo os autores desse capítulo, em boa parte dos relatos conectados ao absurdo ressoa o nome de Franz Kaka, cuja importância na literatura espanhola é inegável a partir de 1950. Esse interesse pela obra do autor de Praga resultou na aproximação entre o absurdo e o fantástico, gerada pela suspensão ou alteração da lei de causa e efeito nos relatos. Exemplo dessa convivência entre os dois gêneros são os livros Esas sombras del trasmundo (1957), de Luis Romero, e Smith y Ramírez, S. A. (1957), de Alonso Zamora Vicente. São obras que não apenas tratam da falta de sentido da existência como também aprofundam o tema dos acontecimentos inexplicáveis e questionamentos metafísicos. Em muitos desses relatos o fantasma ocupa uma posição relevante. Outra característica importante é o tema da frustração individual e coletiva. Zamora Vicente, por exemplo, confere às suas narrativas um toque borgeano ou cortasiano, que se deve seguramente aos 
anos nos quais o escritor passou em Buenos Aires. Esse intercâmbio literário proporciona muitas novidades ao tratamento do gênero fantástico na literatura espanhola de então. Para aqueles que buscam uma autoria feminina nas narrativas fantásticas, geralmente marginalizadas nessa época, também encontrarão autoras como Mercedes Salisachs. A maioria dos escritores dessa geração optou por uma literatura mais comprometida e mimética. Contudo, muitos que fizeram parte da fase neo-realista não excluíram totalmente sua incursão pelo fantástico, como provam o desejo de fuga do cotidiano e a busca por uma realidade transcendente por parte de alguns protagonistas dos contos de Ignacio Aldecoa, Carmen Martín Gaite ou Jesús Fernández Santos. Nos relatos de Ana Maria Matute, essa negação da realidade cotidiana é facultada às crianças, já que quando entram na fase adulta acabam renunciando a esse mundo de magia e maravilha em que se encontravam. Contrastando com o fatalismo de suas produções, outros relatos como os de Medardo Fraile promovem uma dada poetização do real que resulta em uma atmosfera maravilhosa e cria uma dimensão simbólica onde a ilusão impera sobre a falta de esperança. Várias especificações sobre personagens, temas e títulos de obras literárias enriquecem as análises e os comentários dos autores sobre as produções desses decênios. Como conclusão, os escritores registram uma observação muito pertinente sobre as produções dos autores exilados desse período, menos cerceados pela onda realista que imperou na Espanha, e que contribuiu ainda mais para estigmatizar e marginalizar a literatura de corte fantástico, sob o frágil argumento de que este tipo de produção não oferecia uma reflexão crítica sobre a situação do indivíduo e 
seu momento social. Os comentários críticos dos autores sobre o conjunto das produções não miméticas dessa época mostram justamente o contrário desse juízo, além de demonstrarem que os exilados puderam gozar de ampla experiência literária porque não se submeteram a uma visão unívoca de literatura.

Os últimos anos do franquismo marcam o florescimento do gênero fantástico nos mais diversos meios, ou seja, um boom que abarca romances, contos, quadrinhos, filmes, dramas, revistas e seriados de TV. O capítulo que se segue, intitulado "Narrativa 19601980", é de autoria de Miguel Carrera Garrido, que analisa essas produções separando o joio do trigo ao demonstrar que nem todas apresentam o mesmo valor artístico. Mesmo assim, foi graças a esse florescimento que ocorreu a progressiva aclimatação do gênero fantástico na Espanha, processo que Roas e Casas denominam "normalização de los años 80", amplamente tratada por eles em Voces de lo fantástico en la narrativa española contemporánea (2016), obra que comprova o esplendor atual que o fantástico goza em solo espanhol. Nesse complexo panorama traçado por Carrera Garrido, recebe destaque o papel desempenhado pela literatura hispanoamericana na consolidação do fantástico espanhol, sobretudo, a publicação de inúmeras Coleções e Antologias que contribuíram não apenas à divulgação do fantástico e suas metamorfoses como também ao despertar do gosto do público leitor por essas produções. Papel preponderante representou, ainda, os periódicos da época. Borges, Cortázar, Rulfo e Sábato passaram a ser referências de prestígio aos jovens escritores identificados com o insólito e suas facetas, tanto quanto Poe, Kafka ou Hoffmann. Antologias de contos de mistério e terror contribuíram para refletir sobre a 
relação entre o fantástico, o terror e as enfermidades da mente. Vale destacar que de acordo com Carrera Garrido na década de 70 o gênero fantástico estava plenamente consolidado na Espanha, embora ainda muito ignorado pela academia. São mencionadas nesse capítulo antologias e autores de fundamental importância aos que desejam se dedicar ao estudo amplo e aprofundado do fantástico espanhol. O capítulo está dividido em 6 blocos temáticos sobre autores e obras, além de reconhecer sua dívida com os estudos de Roas e Casas como a Antologia que estes publicaram sob o título de La realidad oculta, cujo prólogo descreve em detalhes as produções espanholas fantásticas dos anos 60 e 70 . O segundo bloco, intitulado "entre o fantástico y lo maravilloso", é dedicado à narrativa do galego Gonzalo Torrente Ballester e sua obra, que oscila entre o fantástico genuíno e suas vertentes irmanadas. Já o terceiro, "entre lo literal y lo figurado" saltam à vista as narrativas que não necessariamente se enquadram no esquema todoroviano clássico sobre o fantástico, mas podem ser lidas em interface com este. É o caso de obras que se situam na fronteira entre a imaginação e a realidade, dialogando com o romance policial, com o terror, com o absurdo kafkiano, enfim, de caráter híbrido, mas que tem como elemento unificador o medo, como Las noches lúgubres, de Alfonso Sastre. Esse autor se destaca pelo caráter crítico de suas obras, que conseguem dialogar com a realidade carcomida pela ditadura fascista por meio de estratégias não miméticas, incorporando motivos como o vampirismo, a metamorfose, a ressurreição de mortos, dentre outros, associando-os à alienação, à ressurreição do nazismo, à exploração social e, mais que tudo, ao terror que pairava sobre a sociedade de seu tempo. O quarto bloco, "entre el juego 
y la experimentación", refere-se aos anos 60 e 70, reconhecidos como os anos de experimentação na narrativa espanhola. Nessa Espanha cinza, cansada de vigorosos anos de franquismo e exausta das representações miméticas, surge na literatura o anseio pela experimentação formal na qual a escritura acaba se tornando, muitas vezes, auto-referencial. Tal redimensionamento ocorre não apenas no plano estrutural e linguístico, mas também temático. É nesse cenário que desponta a figura de Carlos Edmundo de Ory. Devido às experimentações estéticas desse momento, muitas modalidades conectadas ao onírico e ao absurdo tendem a um processo amplo de desrealização que termina colocando em questionamento a própria natureza do gênero fantástico, uma vez que este está fundamentalmente ancorado na realidade e o sobrenatural somente pode ser reconhecido ou identificado no seio do real. A quinta parte do capítulo, "entre el homenaje y la apropiación", aborda os autores que mais se destacam no cânone da grande literatura do último século, na qual a prática do fantástico não se deve apenas ao fato de os autores serem leitores desse gênero, mas pela inclinação natural de suas poéticas ou formas de compreender a criação literária. Esses autores contribuem verdadeiramente com a legitimação de gêneros literários populares. São eles o madrilenho Juan Benet, que flerta com o gênero policial e para quem a literatura consiste em uma fonte a mais de conhecimento, além da razão e da ciência, por refletir as ambiguidades e incertezas dos enigmas que rondam nosso universo. Suas obras também aludem ao gênio de Poe, apresentando elementos góticos como espaços opressivos, maldições familiares, fantasmas. Outra companheira de sua geração é Carmen Martín Gaite, que costuma ser mencionada pela crítica 
por sua obra El cuarto de atrás (1978), considerada um autêntico exemplo de transgressão fantástica e onde o fantástico costuma estar a serviço de uma reflexão autoral, ou seja, à sua reinvenção como escritora e à captação da atenção do leitor. O tópico 6, "entre la evasión y la comercialidad", refere-se à popularidade que as narrativas fantásticas alcançaram no final do século $X X$, atingindo recordes de consumo. São caracterizadas pela presença do terror e se aproximam dos romances detetivescos e de mistérios.

No capítulo 5, "Teatro 1900-1960", os autores Matteo De Beni e Mariano Martín Rodriguez afirmam que o conflito entre o natural e o sobrenatural gera uma ambiguidade epistemológica em relação à realidade consensual. As certezas nas quais se assentam a existência humana são abaladas toda vez que irrompe no seio do cotidiano o fato inexplicável. Esse capítulo penetra em um tema espinhoso e complexo que diz respeito às possíveis limitações que geralmente são impostas à representação teatral do gênero fantástico. Portanto, os autores proporcionam um panorama sobre as principais vias de infiltração e modos de representação dos elementos fantásticos no teatro dos séculos XX e XXI na Espanha. Sob o título de "ValleInclán, el simbolismo y lo atávico" são pontuadas as influências do simbolismo no teatro de fins do século XIX e começo do século XX. Dessa fonte foi beber Valle-Inclán, que agregou ao seu teatro as propostas simbolistas que reivindicavam o maravilhoso popular. Conectado a elementos do maravilhoso folclórico, esse autor atribui à representação do maravilhoso uma conotação erótica, que parte da intersecção entre o humano e o animal. Esse hibridismo se faz presente em suas peças de ambientação rural como El embrujado, onde a protagonista tem o poder de enfeitiçar e transformar 
homens em cachorros brancos. Em algumas peças sobressai a explicação racional possível para alguns elementos sobrenaturais, embora permaneça ainda a dúvida em razão da materialização de um presságio. A essa representação do sobrenatural os autores conferem importância ao aparato tecnológico, especialmente, aos efeitos luminosos no cenário. Outra subdivisão desse capítulo trata de "lo fantástico en el teatro popular: Rambal, el mago de la escena española". Nesse bloco, os autores comentam a produção de Enrique Rambal, um empresário e homem do teatro especializado em surpreendentes e refinados recursos utilizados na representação de exitosas obras literárias e cinematográficas. Na parte intitulada "entre los años 40 y 50, en el exílio: Salinas y Casona", os autores comentam a obra de dois dramaturgos que escreveram obras fantásticas no exílio durante a ditadura franquista na Espanha: Pedro de Salinas e Alejandro Casona. Na sequência, o texto se subdivide em mais um bloco temático intitulado "El teatro fantástico y la escena comercial en España en torno a 1950", onde se comenta que o teatro fantástico espanhol apenas alcançaria seu merecido prestígio ao final da Guerra Civil Espanhola. A tecnologia empregada em prol de efeitos especiais de luz e som é sempre referida pelos críticos como suporte que possibilita a dramatização de cenas com efeitos sobrenaturais. Outra dramaturga de relevo em meados do século XX na Espanha foi Julia Maura, que com a ajuda da mencionada tecnologia conseguiu colocar em cena uma peça que brinca com a percepção do tempo e do espaço, na qual coincidem dois tempos em um mesmo espaço, o dos personagens situados em 1939 e o dos fantasmas de 1870. A crença em outras dimensões do tempo também partia de bases racionais como a que expõe J. 
W. Dunne em sua obra Experiment with time, de 1927, traduzida ao espanhol em 1928, onde o tempo é concebido como um espaço geográfico percorrido por uma mente sonhadora e visionária. Essa teoria foi usada por dramaturgos britânicos e espanhóis em suas peças de cunho fantástico, tais como J. B. Priestley, Luis Escobar e Julia Maura. Esta última se utiliza da teoria do tempo para o seu teatro de fantasmas que, segundo os autores desse capítulo, tem a intenção de destacar as consequências históricas da guerra sobre as mulheres. Em suas peças as mulheres, mesmo as emancipadas, são vítimas da brutalidade bélica e masculina. Essa sobreposição de planos temporais também é utilizada por Alfonso Sastre, dramaturgo espanhol.

No capítulo 6, "Cine 1900-1965", Paul Roig realiza um panorama da história do cinema fantástico espanhol do referido período, afirmando de antemão que este não existiu, em seu sentido restrito, até 1968. Na primeira parte de seu ensaio, Paul Roig descreve uma série de obstáculos que impediram o desenvolvimento do cinema espanhol da primeira metade do século $X X$, dentre eles, a censura católico-militar do governo de Franco. Com exceção da obra de Chomón, o estudo do cinema espanhol desse período ainda não foi realizado. Mesmo assim, o autor aponta algumas raras produções e seriados que se tingem de uma temática e de uma atmosfera de terror nos primeiros anos do século $X X$ na Espanha. Até 1929 parecem predominar algumas poucas produções e séries de terror, assim como aquelas de caráter vanguardista ou comédia "costumbrista" tradicional. Nem mesmo a chegada do cine sonoro a partir de 30 e tampouco o advento da Segunda República ou o início da Guerra Civil Espanhola foram capazes de alterar essa realidade 
e, ainda nesse período, Espanha contava apenas com escassas produções oriundas de adaptações literárias e com a falta de roteiristas profissionais. Assim, predominava um cinema de evasão, musical e de entretenimento nesses agitados anos de mudanças políticas e sociais, com raras produções urbanas de caráter policial e de mistério. Se antes da Guerra Civil Espanha não contava com uma política clara de desenvolvimento cinematográfico, também não pode contar com ela nos anos subsequentes. Durante os anos 50 Espanha aprecia o auge do cine policial, sobretudo, produzido em Barcelona. Roig afirma que esse gênero cinematográfico se aproxima do terror, lançando, assim, uma série de psicopatas e assassinos em série, bem como loucuras e alienações mentais de todo tipo. Toda essa gama de produção que se enquadra em um gênero maior denominado thrill não pode ser considerada como cinema fantástico segundo o autor desse ensaio, visto que nenhum deles questiona a ideia comumente aceita de realidade. Outra corrente que se situou à margem do cine fantástico nesse período foi a chamada Spanish Gothic, uma série de ficções ambientadas em uma Espanha profunda, mas que não apresenta elementos mágicos, sobrenaturais ou próprios da ficção científica. Muitos afirmam que Gritos en la noche marca o início do cinema fantástico na Espanha, mas Roig acredita que esta afirmação deriva da confusão, inclusive no meio acadêmico, entre cinema fantástico e cinema de terror, dois gêneros distintos com determinados elementos comuns. O cine de terror conta apenas com uma atmosfera gótica e não propriamente com o elemento sobrenatural fundamental ao gênero fantástico.

De acordo com Iván Gómez, autor do capítulo 7 "Cine 19651990", a partir dos anos 60 surge uma nova preocupação que passa 
a tomar conta do cenário nacional espanhol. Trata-se da criação de películas capazes de projetar uma imagem positiva da Espanha no exterior. Uma nova linha de crédito impulsiona os anos de 1964 a 1969 e fórmulas ligadas ao fantástico, ao terror e à aventura. Apesar de não ser o único, é Jesus Franco quem encabeça a produção cinematográfica espanhola entre 1966 a 1969, com um total de 16 películas. Muitos críticos e historiadores qualificam os anos 70 como a década do cine fantástico espanhol. Além da assimilação de elementos da cultura popular, o gosto pelo cinema fantástico foi desenvolvido pelos grandes cineastas como Jesus Franco, Amando de Ossorio e Jacinto Molina. Um elemento comum em todas as películas dos anos 70, segundo Gómez, é a presença do monstro como elemento desestabilizador. Apesar de um explícito apelo comercial, o autor se pergunta sobre o caráter transgressor dessas produções, já que ao fundarem uma "monstrocultura" não caminhavam, seguramente, de costas ao contexto social de violência e repressão que vivia a Espanha nessa época. Os anos de Transição espanhola, marcados pelo fim de uma censura que vigorou durante décadas, assim como a morte de Franco em 1975, afetaram diretamente o desenvolvimento do cinema espanhol, abrindo-se a uma maior diversificação do mercado cinematográfico onde o grande desafio do gênero fantástico foi competir com o cine erótico que a partir da abertura democrática passou a ser a bola da vez. Em meados dos anos 80 até 1989 constata-se maior irregularidade na produção do gênero fantástico, que passa por um momento de declive, com o progressivo desaparecimento da "monstrocultura", além de uma televisão que não apostava em produtos de corte fantástico. Diante desse quadro, Gómez 
propõe uma reflexão que tem como centro o papel da televisão como grande catalizador de tendências e êxitos cinematográficos, retroalimentando o gosto popular por determinados gêneros e produtos. Assim, a não continuidade de programas como Historias para no dormir na televisão espanhola dos anos 80 contribuiu para o crescente desinteresse pelo fantástico.

Ada Cruz Tienda, no capítulo 8, desenvolve um histórico crítico sobre a presença do fantástico na televisão espanhola, entre 1960 a 1990. Ao assumir a direção da TVE, em 1963, Ibáñez Serrador foi aos poucos introduzindo gêneros como o terror, a ficção científica e o fantástico que até então não eram vistos nesse suporte. Menção especial obteve esse diretor com sua adaptação pessoal de Poe em 1964. O auge de sua produção televisiva, que incorporou o suspense, o terror, a ficção científica e o fantástico, foi Historias para no dormir. Alguns episódios dessa série também privilegiam o policial. Os episódios centrados no fantástico passaram a ser exibidos a partir de 1966, muitos deles inspirados em Poe, em romances de Henry James, em textos de Jiménez del Oso e Juan Tébar. O sucesso da série residiu no fato de Serrador conseguir dosar a medida justa do terror de modo a agradar uma ampla parcela de espectadores. A partir disso, há um aumento no cultivo do gênero não apenas na televisão, mas também no cinema, no rádio e no mundo editorial. Um grande número de roteiristas apostou no fantástico televisivo e adaptou à tela textos de Henry James, Prosper Mérimée, Poe, Le Fanu, Maupassant, etc. A década de 70 demonstrou um intenso interesse pelo gênero. São freqüentes também relatos que mostram objetos com influência maligna sobre o humano ou o motivo da obra de arte 
que ganha vida. Tanto a prosa de Poe como a de Bécquer tiveram um papel especial nos programas televisivos. Progressivamente, novas formas de fantástico foram introduzidas na televisão por Antonio Marcero e o escritor e roteirista José Luis Garci. São obras onde despontam o insólito com ecos kafkianos. Contudo, a partir de 1975 há um contínuo declínio do gênero fantástico no meio televisivo. Essa desaceleração do fantástico na televisão coincide com os anos da Transição democrática. Ao contrário do que ocorreu na narrativa, onde Roas e Casas apontam para uma fase de "normalização do fantástico" nos anos 80 , o meio televisivo teria que esperar até a década de 90 para que uma conjuntura favorável fizesse retornar o seu cultivo na televisão. A conclusão a que chega a autora do capítulo é a de que nas primeiras décadas de existência do fantástico este bebia nos clássicos literários e, no novo século, predomina o texto original, ambientado no tempo e no espaço em que habita o telespectador.

O capítulo 9 trata da narrativa espanhola fantástica entre 1980 a 2015, por David Roas, Natália Álvarez e Patrícia García. Os autores mencionam diversos escritores e obras que configuraram as novas vozes do fantástico na literatura e destacam que essas vozes foram formadas não apenas pelos referenciais nacionais e estrangeiros já mencionados, mas também pelo mundo audiovisual (cine e televisão), além dos quadrinhos e dos games. Também advertem os críticos que essas novas vozes se distinguem por uma poética própria que leva em conta alguns aspectos principais: a justaposição conflituosa entre distintas concepções de realidade; as alterações de identidade; o recurso de dar voz ao Outro; a hibridização dos gêneros e categorias de espaço e 
tempo como agentes do fantástico. Cada uma das categorias dessa poética é amplamente explicada, com fartos exemplos, pelos autores desse capítulo.

A obra organizada por Roas tem o mérito de abarcar todo tipo de produção narrativa, seja em papel, seja em audiovisual, oferecendo ao leitor uma compreensão ampla da cultura do fantástico na contemporaneidade espanhola. Desse modo, o capítulo 10 trata de uma modalidade cada vez mais prestigiada pelos leitores: o miniconto ou microficção. Trata-se de um ensaio escrito por Raquel Velázquez que, em primeiro lugar, descreve o contexto em que o gênero ganha amplas proporções. Para explicar o boom da microficção deve-se, segundo a autora, buscar os condicionantes sociais na vida moderna, incompatível com a leitura de textos longos, assim como a cultura do hipertexto, a escrita e a leitura em dispositivos móveis, a necessidade de condensar a informação, entre outras. As próprias editoras tiveram que se adaptar a uma demanda pela literatura breve na era digital e seus novos hábitos. Entre as editoras espanholas que investiram nessa modalidade destacam-se: Páginas de Espuma, de Madrid, e a Thule Ediciones, que privilegiou escritores latino-americanos, facilitando o intercambio entre Espanha e esses países. As antologias coletivas também contribuíram sobremaneira à difusão da microficção, tanto em papel como em plataformas digitais e blogs. Em algumas antologias citadas pela ensaísta o relato breve espanhol, de cunho fantástico, apresenta o tema do duplo, do vampiro, as metamorfoses de animais com dotes humanos, o fantasma, o demônio, as distorções do espaço e do tempo, a ruptura entre as fronteiras da vida e da morte, etc. Uma das antologias que merece 
destaque por reunir escritores assíduos ao cultivo do fantástico é a Antología de microrrelatos, (2013), organizada por David Roas e José Donayre. Geralmente, as compilações que se circunscrevem ao âmbito hispano-americano ou somente espanhol apresentam distintas tipologias de microficções, nas quais a orientação fantástica é apenas uma delas. Ultimamente, as aproximações teóricas dedicadas à microficção proliferaram muito, com a mesma proporção que aumentou também a escritura do gênero. Nesses estudos, Velázquez assinala a referência a certas temáticas que mais se adéquam às formas breves, a presença massiva da intertextualidade, as revisitações aos clássicos bíblicos, helênicos e lendários, aproveitando o conhecimento prévio dos leitores para estender o relato além de seus limites textuais, e um forte vínculo com a organização do fantástico e seus procedimentos. A forma breve do relato se consolida na Espanha a partir dos anos 90 e desde então aumenta também o interesse pela literatura fantástica, principalmente devido à influência de mestres do conto e de microficções hispano-americanas de corte fantástico: Borges, Cortázar, Marco Denevi, Horacio Quiroga, Juan Arreola, Augusto Monterroso. Na América hispânica o gênero microficção já havia despertado com muita força desde os anos 50 . Nesse período, a Espanha também contava com alguns experimentos no gênero com autores como Ramón Gómez de la Serna, Juan Ramón Jiménez, Antonio Fernández Molina, Ana Maria Matute e Max Aub. Contudo, os primeiros volumes de microficção são publicados na Espanha somente nos anos 80 e 90 e neles é perceptível a dificuldade de penetração do fantástico, predominando formas miméticas. De acordo ainda com Velázquez, há nesses primeiros 
volumes muito hibridismo de gêneros. Na primeira metade do século XXI são publicadas diversas antologias organizadas por seus próprios autores, sobretudo aqueles nascidos antes de 1960 e que cultivaram o gênero microficção até os anos 90 . Nelas não aparecem apenas as conexões limítrofes com o fantástico como também as marcas vanguardistas. Uma coleção que se destaca nessa primeira década é a de Juan Gracia Armendáriz, de 2008, cuja origem dos minicontos é o correio eletrônico, mesclando metaliteratura e fantástico. Já a segunda década do XXI se abre com uma nova publicação de Roas, o volume de contos e microficções Distorciones (2010), que reúne as assimetrias ocultas pela realidade. Do mesmo ano também é a proposta híbrida de Felipe Benítez Reyes, que buscou a interação entre palavra e imagem por meio de colagens relacionadas ao surrealismo, ao absurdo e às raízes do fantástico. Outros autores também publicaram nesse período volumes de microficções que mantêm conexões com o surrealismo, a recriação de mitos e o biofantástico, ou seja, a fusão de elementos fantásticos e biográficos. Em todos os escritores mencionados o interesse pelo fantástico parte de uma visão poliédrica da realidade. Para Velázquez, o conceito de real na atualidade inclui a desorientação do indivíduo, a desconstrução de planos e a inserção de coisas impossíveis. São histórias que questionam as novas teorias físicas e científicas e a limitação de nossos sentidos. As microficções fantásticas são, assim, o resultado da ruptura entre as fronteiras que separam umas realidades das outras, enlaçando multiuniversos com os sonhos, com a ficção científica, a literária ou cinematográfica, assim como personagens monstruosos e fragmentados. 
O texto de Teresa López-Pellisa e Mateo De Beni compõe o capítulo 11 desse compêndio da cultura fantástica espanhola e versa sobre o teatro no período de 1960 a 2015. Esse capítulo oferece uma visão panorâmica dos autores, obras e temas mais relevantes do drama fantástico espanhol. Nos anos 60, a Espanha vive uma abertura sócio-cultural e surgem vários grupos de teatro estudantil à margem do sistema oficial, com espetáculos subversivos e experimentais. Nesse período, são apresentadas obras até então censuradas como as de Bertold Brech. Uma década antes, Espanha vivia o predomínio do drama realista ou social. Francisco Nieva, Alfonso Sastre e Domingo Miras são autores nascidos em 20 e 30 que os críticos ressaltam como cultivadores de aspectos do fantástico na dramaturgia espanhola. Para tratar das obras fantásticas de Nieva, os autores recorrem à sua dramaturgia breve, publicada em 1987, ora marcada por uma regressão cronológica perturbadora ora por um terror fantástico com traços de macabro. Já Alfonso Sastre sempre demonstrou ao longo de sua trajetória uma devoção pelo terror e pelo mistério, como revelam várias de suas obras publicadas a partir da década de 50. Portanto, os críticos o consideram um grande conhecedor dos recursos cênicos da literatura fantástica e de terror. Em peças como Las cintas magnéticas (1971), Sastre insere episódios de licantropia para criticar os horrores da guerra no Vietnã. Para este dramaturgo, as formas não miméticas e pictóricas também são realistas porque representam sempre a realidade social e seus problemas. A esse respeito os autores lembram, ainda, os estudos de Luisa García-Manso que se referem ao teatro contemporâneo espanhol como uma via de recuperação da memória de episódios 
traumáticos da Guerra Civil, da ditadura franquista e do exílio por meio da voz encarnada por personagens vindos do além. Os anos 80 são os anos da renovação das artes cênicas e se caracterizam pela experimentação, pelo teatro de rua, pela proliferação de performances, pelos musicais, etc. Segundo López-Pellisa e De Beni, diversos autores do novo milênio, mencionados nesse capítulo, transitam entre o fantástico, o simbólico, o alegórico, o distópico e a ficção científica. As adaptações literárias de clássicos do fantástico do século XIX se convertem em musicais no século $\mathrm{XXI}$. Os espectros, os licantropos, as almas penadas, humanos metamorfoseados em bestas, os monstros, todos formam parte da tradição teatral espanhola. A literatura dramática na Espanha não se definiu apenas pelo realismo. Nos textos dos séculos $X X$ e XXI a dramaturgia se serve do mimético e do não mimético para representar a realidade.

O capítulo 12, sobre o cinema espanhol entre 1990 a 2015, é de autoria de Rubén Sánchez Trigos. Este afirma que o início dos anos 90 representou um divisor de águas na renovação cinematográfica espanhola. Em primeiro lugar deve-se levar em conta que a globalização influenciou a forma com que os novos cineastas e as novas gerações de público se aproximam de determinados gêneros e à ideia de que o moderno cinema espanhol, de caráter fantástico, convida a questionar e examinar a tradicional noção de cine espanhol aceita pela crítica e por parte dos espectadores. Nesse período de renovação entra em crise um modelo de produção de baixo custo vigente durante os anos 70. Passou a predominar no panorama cinematográfico de então um modelo referencial de peças, sejam elas as que seguiam os postulados formais da clássica série B ou as 
que mantinham um modelo de fantástico intelectualizado, iniciado em 60 e 70. As novas condições que moldaram a indústria e o mercado cinematográfico espanhóis estão voltadas aos incentivos que as publicações de revistas sobre o fantástico receberam e que impulsionaram os cineastas emergentes a cultivarem o fantástico nos últimos anos da década de 80 e início dos anos 90. Estas publicações, responsáveis pela difusão e divulgação de películas fantásticas espanholas, foram denominadas em sua totalidade de universo fandom. Esse universo constitui um documento cultural importante sobre as atividades discursivas dos usuários do gênero, proporcionando informações sobre as subculturas que integram esse universo, revelando um atlas da cultura de horror espanhola e a relação deste universo com os festivais voltados ao gênero. Também dá mostras da vitalidade do fantástico em outros meios como os quadrinhos, o próprio cinema e as revistas e fanzines. A partir da Carta Magna da Lei Miró, em 1983, que tinha como objetivo incentivar a renovação e revitalização cinematográfica espanhola, tornaram-se conhecidos muitos diretores de cinema que então iniciavam suas carreiras. Em 1996, José Maria Otero, que ocupava a Direção Geral Cinematográfica, em vez de seguir as diretrizes da Lei Miró de incentivo aos jovens diretores decide premiar as películas de êxito inscritas em um modelo norte-americano. Os diretores que debutaram nesse período foram agrupados pela crítica oficial sob a denominação de "nuevo cine español". Como resultado dessa política, Trigos adverte que o cine fantástico espanhol desse período consiste em um mosaico de diferentes modelos, tão heterogêneo quanto os que vigoravam na Espanha nos anos 70. De acordo com Jim Collins, há duas tendências em que 
as películas fantásticas norte-americanas se agrupam na década de 90: uma chamada de "hibridização irônica", onde os filmes inserem em seu discurso recursos de outros gêneros, criando novas misturas, e a "nova sinceridade", categoria que abarca aquelas películas que mantém relativamente separado os elementos canônicos do cine de terror, evitando a ironia da primeira categoria. Esses modelos elencados por Collins também servem, segundo Trigos, para abarcar as manifestações do fantástico no novo cine espanhol, englobando ainda a estréia de alguns cineastas como Amenábar ou Ballagueró. Como contribuição ao entendimento da complexidade desse período, o autor do presente capítulo acrescenta um terceiro modelo à categorização dual proposta por Collins e que trata, portanto, das formas com que o cine espanhol do passado se aproximou do gênero fantástico, desde a comédia "fantaterrorífica" ao fantástico de raiz mais ou menos literária, cultivado por diretores como Gonzalo Suárez. Parece não ter sido cultivada, antes de 1990, a hibridização irônica no cine espanhol, exceto hibridização comédia-fantástico, presente na tradição comédia "fantaterrorífica". Partindo dessa categoria, será Álex de la Iglesia quem ajudará a popularizá-la no cine espanhol a partir dos anos 90, desenvolvendo nesta novas possibilidades. Essas inovações encontraram um novo público por meio de películas que celebram o excesso, identificando-se com esse novo espectador acostumado aos quadrinhos, aos games e ao cine mainstream de Hollywood dos anos 70 e 80. Prova do sucesso entre a conciliação dessa nova geração de críticos e espectadores com velhos valores tradicionais do cine espanhol é a película El día de la bestia, que recebeu o premio Goya em 1995. Apesar das inovações, Trigos menciona que 
a vinculação do fantástico com o cine espanhol popularizado por Álex de la Iglesia a partir de 90 é apenas tangencial. Será necessário esperar até 2013, com Las brujas de Zugarramurdi, para ver uma película claramente fantástica dirigida por Álex de la Iglesia. Foi, contudo, El día de la bestia (1995), que antecipou algumas das principais senhas de identidade do recente cine fantástico espanhol como, por exemplo, o tratamento que o imaginário nacional católico vai receber na série Rec. É a forma com que De la Iglesia manipula a matéria fantástica que marca o futuro desenvolvimento do gênero na Espanha. Após diversas considerações e de enumerar vários títulos de obras cinematográficas, o estudioso afirma existir na Espanha, junto a uma cinematografia standar, uma corrente que aponta para um fantástico genuinamente espanhol, em permanente diálogo com as tradições internacionais do gênero. Outra corrente do cine espanhol fantástico que tem recebido boa acolhida do público é aquela que se baseia na história recente da Espanha para subverter, por meio do efeito fantástico, a convicção que outrora público e personagens alimentavam sobre a realidade, propondo, assim, novas formas de interpretar aspectos sócioculturais problemáticos. É o caso da famosa película El laberinto del fauno ou do filme El espinazo del diablo, de Guillermo del Toro, ambientados na guerra ou na pós-guerra civil espanhola e com elementos sobrenaturais, caracterizando o que Trigos identifica como um "fantástico histórico".

O penúltimo capítulo compreende a Televisão, de 1990 a 2015, de autoria de Paul Patrick Quinn. Tem como propósito oferecer uma análise do fantástico televisivo na Espanha durante o período selecionado. Para tanto, o autor divide o capítulo em dois blocos 
temáticos: um sobre a evolução de um subgênero televisivo e outro sobre temas e motivos fantásticos. O primeiro bloco assume uma perspectiva diacrônica, pontuando os fatores que contribuíram à consolidação do fantástico televisivo, assim como a relação das principais séries. O segundo bloco assume uma perspectiva diacrônica e sincrônica que enfoca os cronotopos do terror, a mise em abyme, o jogo de temporalidades e figuras fantásticas e históricas como fantasmas, vampiros e seres híbridos. É aproximadamente em torno de 1995 que, segundo Quinn, são assentadas as bases do boom da televisão fantástica espanhola que viria a ocorrer no século XXI. Essas bases são formadas pelas vertentes do realismo "costumbrista", pela multitrama e pelo hibridismo dos gêneros, bem como a aproximação à linguagem cinematográfica e surgimento de um segmento de público juvenil urbano. No que diz respeito às tendências temáticas, despontam motivos como a dissolução da realidade familiar, com lares desestruturados, representando as transformações da família espanhola tomada pela instabilidade conjugal e suas consequências nos filhos, ou seja, a crise do clã familiar tradicional e a criação de novos formatos de família. Quando menciona o fantástico na televisão espanhola dos anos 90, o autor faz questão de distinguir entre o gênero e o formato. O primeiro diz respeito ao conteúdo e a temática, que fazem do fantástico um gênero poroso e híbrido, irmanado à ficção científica e ao terror. Já o formato, diz respeito ao que define Carrasco Campos quando se refere a um conjunto de formas que diferenciam um programa de outro sem recorrer a critérios temáticos. Sobre o que se refere ao formato, o gênero televisivo fantástico espanhol dos anos 90 assume a categoria de séries de antologia. Em cada capítulo dessas 
séries mudam os personagens e cenários, até mesmo a equipe de produção. Há um elenco diferente para cada relato, com tramas fechadas e auto-conclusivas. Apenas uma década depois surgiria o formato multitramas e tramas horizontais. As séries de antologia constituem um formato adequado ao terror e ao mistério que em Espanha tem como antecedente a famosa série Historias para no dormir (TVE, 1966-1982), de Narciso Ibáñez Serrador, que continha a adaptação de textos completos de Poe e Ray Bradbury, ocupando um papel transcendente na história da televisão espanhola. As séries de antologias dos anos 90 apresentam temas como o duplo diabólico, a casa mal assombrada o homem lobo e o zumbi. Um exemplo é a série Historias del otro lado (1991-1996) sobre cadáveres que se levantam das tumbas, vidas paralelas e alterações de tempo e espaço, profecias de morte e quadros malditos. Outro destaque dos anos 90 são as adaptações dos Contos de Borges (TVE, 1992), onde aparecem vários relatos tomados da obra El Aleph, com roteiros de Fernando Fernán Gómez e Victor Erice, com especial destaque para "El Sur", que combina o sonho e a vigília com alusões à vida do escritor argentino, ou a série Me alquilo para soñar (1992) baseada em Doce cuentos peregrinos de Gabriel Garcia Márquez, com conotações claras de realismo mágico. Apesar das escassas séries fantásticas televisivas dos anos 90, o autor afirma que já havia nessa época um público faminto por histórias terríficas. Um fenômeno binário de transformação será crucial para o boom do fantástico televisivo a partir dos anos 2000. Essas transformações, gestadas na última década do século $\mathrm{XX}$, se referem à capacidade elevada dos realizadores e à queda dos preconceitos em relação ao cine fantástico por parte dos jovens de 18 a 30 anos. Quinn 
esclarece que o boom das séries fantásticas de TV do século XXI é o resultado de dois impulsos, um centrífugo, de americanização, influência e presença dos padrões estético-temáticos da indústria audiovisual norte-americana e outro centrípeto, de aproximação "costumbrista" e inevitavelmente ideológica à realidade espanhola. Também proliferam, por outro lado, os ciclos televisivos dedicados às séries de terror. Tudo isso junto contribuirá ao êxito da ficção fantástica televisiva a partir do ano 2000.

O último capítulo, que fecha com "chave de ouro" essa obra de referência sobre o fantástico na cultura espanhola contemporânea, é redigido por José Manuel Trabado Cabado e tem como tema o fantástico na Narrativa gráfica, de 1990 a 2015. Como grande expoente da representação gráfica do insólito é citada a obra de Winsor McCay, publicada em 1905. Essa influência poderosa de McCay logo passa a ser sentida na Espanha, que em 1907 publica suas obras sob o título de Los sueños de Manolín, na Revista La Semana Ilustrada. Todas as mudanças empreendidas na tradução da obra de MacCay ao espanhol resultaram na transmutação de uma vertente de cunho fantástico a uma obra de vertente realista. Apesar de tudo, a iniciativa de divulgar MacCay teve repercussão em solo espanhol, visto que a partir disso surgiram outras séries fundamentadas na premissa oníricofantástica, como a intitulada Las pesadillas de Miguelín, publicada na Revista Alegría, em 1908. Cabado assinala uma característica marcante nos quadrinhos espanhóis, que é o efeito irônico para referir-se a questões político-sociais da atualidade. Na série sobre Las pesadillas de Miguelín, de 1908, o discurso aparentemente voltado às crianças consiste, na verdade, em uma crítica, por meio 
do discurso humorístico, aos problemas sociais espanhóis daquele período. Esse discurso se distanciava da diretriz universal do onírico proposto por MacCay, voltava-se mais ao público adulto do que ao infantil e deixava transparecer a ideologia editorial da Revista La Semana Ilustrada. Somente após a Guerra Civil nos anos 40 os quadrinhos cultivaram outros núcleos temáticos, especialmente as aventuras, núcleo ao qual o fantástico será submetido, ao lado da ficção científica e do terror, na busca de um público infantil. Em 1945, alguns cadernos surgiram com temas fantásticos como El hombre invisible e La sombra de Frankenstein. Outras iniciativas que colocam o fantástico mais ao centro vão surgindo no final da década de 40, com histórias de corte terrífico e policial. Contudo, quando o fantástico parecia alçar vôo nos quadrinhos surge um novo retrocesso que levou ao desaparecimento do fantástico nesse suporte em 1952, com as Normas sobre a Imprensa Infantil e Juvenil. Na década de 50 verifica-se um movimento bem expansivo da ficção científica, que continua articulando-se com o fantástico até a década de 60 . Somente a renovação político social e editorial dos anos 70 abriu a oportunidade para a entrada do fantástico nos quadrinhos, rompendo com o modelo pós-guerra vigente até esse momento. Com essa abertura mais democrática, as historias sentimentais dão lugar à fotonovela e a telenovela, mas somente com a revista Drácula, publicada a partir de 1971, o gênero fantástico finalmente vingaria. Foi pelas mãos de Buru Lan que o panorama fantástico dos quadrinhos espanhóis se renovou, como exemplifica a revista Drácula. Além do programa editorial de Buru Lan e da aparição de uma gama de revistas de terror nos anos 70 , outros periódicos 
propuseram uma renovação dos quadrinhos. São aqueles criados por Toutain. Neles se conjugam o fantástico e a ficção científica e todas as histórias são auto-conclusivas, girando em torno de um mundo absurdo de corte surrealista, baseado na deformação da realidade e na qual um acontecimento cotidiano desencadeia uma série de fatos ilógicos; já outras seguem as matrizes temáticas da ficção científica. É Prado quem com sua obra Ardalén atinge a excelência do que se denominou romance gráfico fantástico. Prado teve como referente Álvaro Cunqueiro e escritores latinoamericanos como Borges e Cortázar. Na origem de seu romance gráfico aparecem quadros do próprio Prado, sempre repletos de criaturas marinhas e muito lirismo, refletindo imagens de um mundo paradoxal. Emprega uma linguagem eclética em suas obras, onde o lirismo serve como via de aprofundamento psicológico das personagens. Sua grande contribuição aos quadrinhos advém dessa proposta inovadora que se afasta um pouco dos registros tradicionais do fantástico como a ficção científica e o terror, vigentes nos anos 80. Desde seu surgimento, o romance gráfico parece nutrir-se de temáticas que fogem do campo da ficção como, por exemplo, a autobiografia, a reportagem jornalística, os diários e os quadros de viagens, promovendo, assim, uma nova forma de narrar distante dos padrões estabelecidos. Nesse universo, buscava-se uma nova forma de contar os acontecimentos insólitos do cotidiano, fugindo assim do tempo das aventuras e cenários exóticos. Dentro desse panorama, é possível pensar que o desenvolvimento do romance gráfico fantástico implicaria em uma nova via de desenvolvimento que se desvincularia das inércias habituais do romance gráfico. É a obra 
Trazo de Tiza que se converte em ponte, nessa ocasião, articulando a cultura das revistas em quadrinhos dos anos 80 à irrupção de um novo mercado editorial que apostava no romance gráfico. Tamanha é a sua visibilidade que influencia na normalização do gênero, resultando na recuperação de autores clássicos e reedição de relatos fantásticos que haviam aparecido no seio das revistas 1984, Zona 84, Cairo e Rambla; todas dos anos 80. Paradoxalmente, será a consolidação do romance gráfico o fator responsável pela recuperação de relatos breves e de matiz fantástico com a nova cultura com a qual passa a estabelecer um diálogo frutífero. Nesse cruzamento entre os quadrinhos tradicionais e os novos romances gráficos que ganha destaque Paco Roca. Esse autor de Arrugas cultivou o fantástico no gênero romance gráfico e também nos relatos publicados na imprensa, depois compilados em forma de livro, nos quais o humor atenua o caráter inquietante do fantástico. Enquanto Arrugas e Los surcos del tiempo não encarnam a poética do insólito outros relatos de Paco Roca o fazem. É o caso de relatos como El faro (2004) e Calles de arena (2009). Ambas apresentam final epifânico, que motiva o autodescobrimento, e apresentam ressonâncias borgeanas. Há nas obras desse autor todo um acervo iconográfico que pode servir de estudos para a poética do fantástico. Outro autor importante que transita assiduamente pelo território do fantástico no romance gráfico é Luis Durán. Um dos temas principais que ele cultiva é a infância e suas memórias. Nelas se vêem a repetição de vários motivos iconográficos que remetem ao tema da infância. A presença do fantástico em seus relatos também gera uma deformação topográfica e a consequente irrupção de novos cronotopos. Atrelado a isso está também a 
linguagem, que passa a representar essa nova visão do mundo por meio de idioletos simbólicos. Nesse panorama eclético e refinado dos quadrinhos espanhóis, o autor diz não poder encerrar sem apresentar a obra Max Bardín el surrealista, que reúne histórias breves, publicadas em distintos lugares, cujo fio condutor é a aparição de um único personagem que encontra uma maneira de ter acesso ao outro lado da realidade, ou seja, uma suprarealidade. Outras informações relevantes apresentadas por Cabado dizem respeito à presença de uma tradição oriental, recheada de sobrenatural, que chega aos nossos dias por meio de obras como 3, calle de los misterios de Shigeru Mizuki (2011), ou Barrio lejano, de Jiro Taniguchi (2003). Também ganham destaque as recentes traduções de MacCay, modelo de fantástico nos quadrinhos nas primeiras décadas do século $X X$. Como conclusão do capítulo, Cabado pontua que o fantástico nos quadrinhos nesses anos iniciais do século $X X I$ tem trilhado um percurso transversal, oferecendo uma arquitetura narrativa que recolhe tanto histórias de gêneros como quadrinhos de autor. O fantástico nos quadrinhos também se apresenta atualmente como fenômeno de articulação cultural, oferecendo uma forma de aprofundamento das emoções, como demonstraram os autores e obras citadas, que parecem ter descoberto no fantástico uma maneira de ir além do medo e da perplexidade. Assim, é possível afirmar que o fantástico chega com toda força aos quadrinhos a partir dos anos 70 , com a contribuição das revistas de quadrinhos e traduções de autores de diversas nacionalidades. Essa presença transversal buscava pontos de conexão entre diversas revistas díspares dos anos 80 e, no final dessa década, quando o chamado boom dos 
quadrinhos adultos veio à tona apareceram exemplos como Trazo de Tiza, que atuou como articulador entre o gênero fantástico, os quadrinhos de autor, as revistas e a consolidação do que anos mais tarde seria o romance gráfico.

Historia de lo fantástico en la cultura española contemporánea (1900-2015), organizada por David Roas, é uma obra indispensável no cenário dos estudos fantásticos de um modo geral e dos estudos hispânicos, de um modo particular. Uma obra inspiradora e de referência aos estudos hispânicos empreendidos tanto no Brasil como no Exterior, especialmente, aos docentes, discentes e investigadores universitários que se debruçam sobre o fenômeno fantástico em narrativas multimidiáticas, compreendendo a literatura, o teatro, o cinema, as séries de televisão e os quadrinhos. Trata-se de uma visão ampla da presença do fantástico e suas vertentes contemporâneas, porém abordada com rigor teórico e metodológico, resultante de uma extensa trajetória de pesquisa empreendida pelo Grupo de Estudios sobre lo Fantástico (GEF) da Universidade Autônoma de Barcelona. A obra conta, ainda, com a colaboração de vários pesquisadores de outras universidades espanholas e estrangeiras que se destacam nessa área de estudos. Sua contribuição é inédita no campo das pesquisas sobre o fantástico e sobre o fantástico espanhol, estimulando outros desdobramentos e aprofundamentos interdisciplinares que acentuam a importância desses estudos não apenas aos investigadores do campo das letras, mas também do meio audiovisual e artístico de um modo geral. Dialogando de modo eficaz com críticos e historiadores da cultura, os diversos capítulos que desenham a trajetória do gênero fantástico na contemporaneidade espanhola propõem 
uma revisão multidisciplinar da abrangência desse fenômeno e de sua função desautomatizadora em diversas modalidades artísticas. A abrangência da interpretação do fenômeno fantástico em multimeios e em múltiplas linguagens não o torna fluído, ao contrário e de forma paradoxal, quanto mais plástico e poroso mais definido e esclarecedor ele renasce, distinguindo-se de outros gêneros com os quais intimamente se entrelaça. Desse modo, o leitor poderá contar com inúmeras sugestões de novas frentes de investigação que permitirão elucidar o complexo universo oculto por trás de nossa aparente realidade. 